\title{
To What Extent Does Hands-On Exposure to Algebraic Thinking Predict Mathematics Achievement for Urban Middle Schoolers?
}

\author{
Azure C. Covington (Corresponding author) \\ Senior Analyst, Charlotte-Mecklenburg Schools \\ 1901 Herbert Spaugh Lane, Charlotte, North Carolina 28215, United States
}

Tel: 1-980-343-4067Ｅ-mail: azure.c.covington@gmail.com

Peter Sheppard

College of Education, University of Louisiana at Lafayette

P.O. Box 42051, Lafayette, Louisiana 70504, United States

Tel: 1-337-482-1514Ｅ-mail: psheppard@louisiana.edu

Tori K. Flint

College of Education, University of Louisiana at Lafayette

P.O. Box 42051, Lafayette, Louisiana 70504, United States

Tel: 1-337-482-6459Ｅ-mail: tflint@louisiana.edu

Nii A. Tackie

College of Education, University of Louisiana at Lafayette

P.O. Box 42051, Lafayette, Louisiana 70504, United States

Tel: 1-337-482-6413 E-mail: ntackie@louisiana.edu

Received: March 5, 2019 Accepted: April 27, 2019 Published: May 10, 2019

doi:10.5296/jei.v5i1.14460 URL: https://doi.org/10.5296/jei.v5i1.14460 


\section{Abstract}

In this study we investigated the relationship between urban eighth grade students' Hands-On Exposure to Algebraic Thinking (HEAT) competition performance and their subsequent performance on standardized measures of mathematics achievement (ACT Composite Score, ACT Math Scores, and Louisiana Algebra End of Course Exams). It was found that the pictorial portion of the project was a relatively consistent predictor of participants' high school academic performance. That is, as participants' HEAT pictorial competition scores increased, so did their ACT composite, ACT math scores, and Algebra End of Course Exam Scores. Findings from the HEAT Project may contribute to conversations centered on ways to expose urban students to creative, social, hands-on pedagogy in non-evaluative contexts in order to position students for both immediate and long-term mathematics success without sacrificing intellectual rigor.

Keywords: Algebra, Linear equation, Pictorial representation, Urban

\section{Introduction}

American College Testing (ACT) (2016) reports that although underserved learners (including African Americans and those deemed economically disadvantaged) have high interest in Science, Technology, Engineering, and Mathematics (STEM) fields, their ACT STEM Benchmark attainment lags far behind their peers in other ethnic groups. This ACT STEM Benchmark is derived from a student's ACT mathematics and science scores and represents their overall performance in these subject areas (ACT, 2016). Additionally, only thirteen percent of eighth grade African American students and nineteen percent of fourth grade African American students scored at the proficient level on the mathematics portion of the 2015 National Assessment of Educational Progress (NAEP) tests. In fact, African Americans have scored significantly lower than other ethnic groups for decades on NAEP assessments (National Academy of Sciences, 2011; National Assessment of Educational Progress, 2016). In order to assist underrepresented groups in successfully meeting their aspirations of entering STEM careers, it is recommended that stakeholders focus on success in mathematics, which is among the most reliable predictors of success in college and the workplace (National Academy of Sciences, 2011). Algebra is particularly important due to the fact that "students who successfully complete Algebra II as their highest high school math course are more than five times as likely as students who only complete Algebra I to obtain a bachelor's degree" (National Academy of Sciences, 2011, p.71).

Accordingly, this paper centers on the Hands-On Exposure to Algebraic Thinking (HEAT) Project, an after-school program, aimed at improving the algebraic proficiencies of students enrolled in six urban middle schools with high percentages of African American students and high percentages of students that receive free/reduced lunch among their populations. The extent to which the use of hands-on manipulatives and pictorial representations support and predict students' future mathematics success (as measured by subsequent standardized tests, etc.) appears to be an understudied topic. The purpose of this paper is to add to the research literature in this area by examining the relationship between urban middle school students' HEAT competition performance and their subsequent mathematics achievement. The central 
research question that guides this study is: To what extent does the HEAT Project predict students' subsequent mathematics performance?

\section{Literature Review}

Many scholars have researched the use of concrete models for solving equations. For example, Vlassis (2002) investigated the use of concrete models in solving linear equations with one unknown, using the formal method that involved performing the same operation on both sides of the equal sign. In this study, students were asked to solve linear equations with one unknown. Findings indicated that the students were able to invoke the principle of the balance (that is, performing the same action on both sides of the equation) to transform equations to equivalent forms in order to solve these types of problems.

Similarly, Araya et al.'s (2010) study randomly assigned 236 seventh grade students who had no prior instruction in algebraic equations to two treatments: One group watched a 15-minute video teaching them how to solve linear equations using algebraic symbolic strategies while the students in the other group watched a 15-minute video teaching them how to solve the same equations using representational metaphors. After the experiment, students from both groups were assessed using equations written in symbolic notation. It was determined that the group that watched the video with the representational metaphor performed significantly better than the group that watched the video with the symbolic approach. The data also revealed that "students with a below-average mathematics GPA who watched the analogies video did as well as students with an above-average GPA who watched the symbolic strategy video" (Araya et al., 2010 , p. 216). Findings from the above studies suggest that it is possible for students to invoke the principle of the balance as an embodiment for helping them learn fundamental concepts related to solving linear equations with one unknown.

Wolfgang, Stannard, and Jones (2001) attempted to establish a correlation between the levels of young children's block play and their performance in mathematics in later school levels. The authors conceptualized play to encompass three aspects including:

1) Sensorimotor play (large and small motor play)

2) Symbolic play-involving representational abilities and including the fantasy play of socio-dramatic play

3) Construction play-involving symbolic product formation with blocks, Legos, carpentry, and similar materials.

Findings indicated, controlling for IQ and gender, that children's play with blocks reliably predicted mathematical achievement at the 7th-grade and high school levels. One explanation for the positive correlation between children's play and their future success in mathematics was that the block play possibly supported the development of underlying cognitive structures which helped the students to perform well in abstract mathematics such as geometry, trigonometry, and calculus. This finding suggests that when students work with representational models, it is possible for them to develop cognitive schemas that can support abstract thinking. In the HEAT program, it is possible that students' direct modeling with 
algebra tiles and pictorial representations, similar to a child's play, might enable students to develop cognitive structures that can support their future work in algebra and geometry. Wolfgang, Stannard, and Jones (2001) findings seem to confirm Vlassis' (2002) view that when students use representational models to learn mathematical concepts, the operative mental image effect is long lasting.

\section{Theoretical Framework}

\subsection{Defining the Term Urban}

In prefacing how this study is framed, implemented, and analyzed, it is important to note how we define urban. In many research contexts, the term urban, is often:

...relegated to an umbrella term used indiscriminately to denote African American, Hispanic, immigrant, or low-income students...furthermore, given that mathematic-achievement gaps are popularly depicted in terms of race, ethnicity, and/or income, the term urban is often utilized as an all-encompassing deficit term. (Matthews, 2008, p. 2)

Herein, we utilize the term urban, as suggested by Matthews (2008), extending beyond geography and into the lives of the students wherein it is understood that multiple cultural, racial, linguistic, social, socio-economic, and political spaces and identities have broad impacts on mathematics learning.

\subsection{Constructivism}

Mathematics educators and researchers suggest that mathematics instruction should support students' conceptual understandings and procedural fluency (Jackson \& Wilson, 2012). Due to the hands-on, active nature of the HEAT Project, it can be viewed, overall, through a constructivist lens.

As a theory of learning based in psychology, constructivism considers the ways in which people learn and suggests that people construct knowledge through experiences and reflections. Constructivism further submits that learning is an active and contextualized process of meaning making. Knowledge is constructed based upon personal experiences and hypotheses drawn from the learning environment and is informed by active participation in learning experiences (Bruner, 1961; Vygotsky, 1978). In the mathematics classroom context, the constructivist view of learning aligns with a variety of different teaching practices. Generally, it entails encouraging students to use active techniques (hands-on learning, real-world problem solving, etc.) to construct knowledge.

\subsubsection{Social Constructivism}

Social constructivism (Vygotsky, 1978) posits that knowledge is first constructed within a social context and is later appropriated by individuals (Bruning, Schraw, \& Ronning, 1999). As an extension of constructivism, social constructivism suggests that learning is an active, social process in which people construct new ideas or concepts in cooperation and collaboration with others (Bruner, 1961; Vygotsky, 1978). Social constructivists further suggest that the process of 
sharing individual perspectives can result in knowledge construction that may not have been possible on individual levels alone (Greeno, Collins, \& Resnick, 1996). Social constructivism not only acknowledges the unique understandings of each individual, but also supports them as integral parts of the learning process in social contexts (Wertsch, 1988). In this capacity, people can share individually constructed knowledge and information and learn from each other. When working together and sharing information, people can discover ideas for themselves through active, hands-on experiences, hypothesis construction, encouraging guesswork, collaboration, and intuitive thinking. Many constructivist scholars agree and emphasize that individuals make meanings through their interactions with others and with their environment(s). Knowledge is thus socially and culturally constructed (Ernest, 1994; Prawat \& Floden, 1994) and learning is a social process (McMahon, 1997; Vygotsky, 1978).

The HEAT Project can be viewed as constructivist/social constructivist in nature, as it focused on the use of instruction/learning that included hands-on materials and activities, such as manipulatives and pictorial drawings, and allowed the students to actively learn through experience as they cooperatively solved problems in a hands-on manner. HEAT framed mathematics learning as an active process, social process focused on conceptually-based instruction.

\section{Hands-On Exposure to Algebraic Thinking Project Synopsis}

The HEAT Project aligns with the National Research Council's (2015) recommendations, which call for utilizing out-of-school-time programs as a means to improve academic achievement in STEM areas for underrepresented groups. Rather than present fundamental aspects of algebra as an abstract concept, the HEAT Project afforded middle grade teachers opportunities to teach said skills using concrete manipulatives and pictorial aids adapted from the Hands-On Equations foundational model (Borenson \& Barber, 2008).

This model consists of a two-pan balance, white and blue pawns, and red and green numbered cubes. The two pans of the balance depict the two sides of an equation, the blue and white pawns represent positive and negative unknown quantities respectively, and the red and green numbered cubes represent negative and positive numbers respectively. To model a linear equation using the concrete manipulatives (Hands-On Equation models), one has to set up the correct pawns and numbered cubes on either side of the pan.

The pictorial aids component of the HEAT project required that one utilize pictorial representations (shown in Table 1) to set up and solve linear equations with one unknown. 


\section{Macrothink}

Table 1. Symbols and their Meanings for the Pictorial Representations

\begin{tabular}{|c|c|}
\hline Symbol & Meaning \\
\hline A triangle $\Delta$ & An unknown quantity, for example, $x, y$, etc. \\
\hline A shaded triangle $\boldsymbol{\Lambda}$ & Unknown negative quantity. For example, $-\mathrm{x}$, $-\mathrm{y}$, etc. \\
\hline A rectangle with a number written $\pi$ & A positive number. e.g., 7 \\
\hline A circle with a number written in it 6 & Negative number. e.g., -6 \\
\hline
\end{tabular}

Note. Pictorial representations used by participants to set up and solve linear equations.

In drawing pictorial representations for a linear equation, one must use the appropriate symbol(s) to setup the equation. To solve a linear equation with one unknown using the Hands-On Equations, one must perform "legal moves" (Borenson \& Barber, 2008) to add or remove pawn or numbered-cubes from either side of the pan balance until a solution is obtained. A legal move is adding or removing pawns or numbered cubes from either side of the pan yet keeping the original equation unchanged. By utilizing legal moves to solve linear equations with one unknown, students are able to see the underlying mathematical concepts and operations carried out to solve a given linear equation. The figure below (Figure 1) indicates a student's pictorial representation of how a verbal linear equation was set up and solved utilizing pictures.

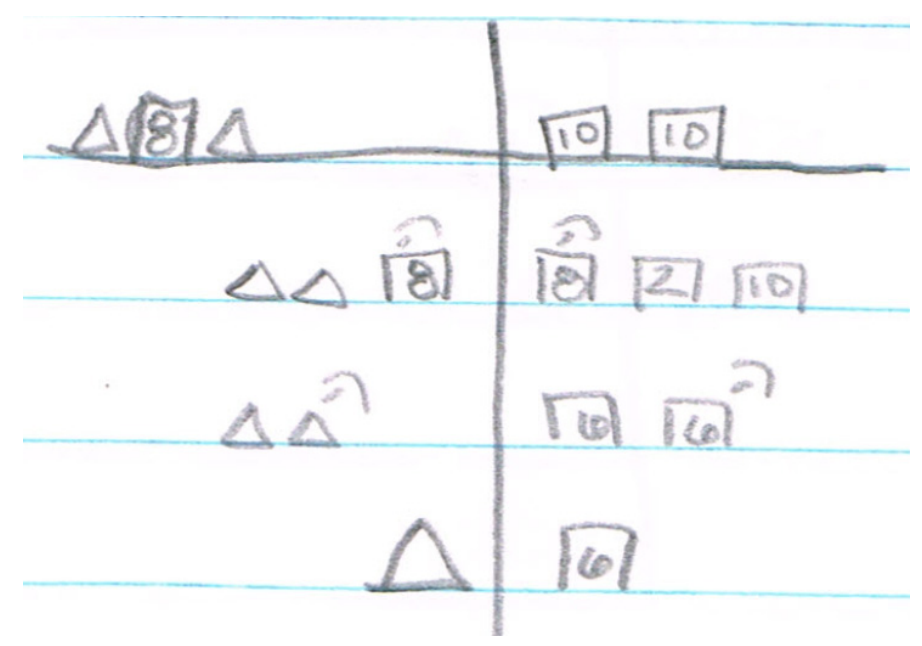

Figure 1. A pictorial representation of linear equation and its solution for the verbal equation: The sum of a number and 8 more than the number is 20 . Find the number

Note. Student's pictorial representation of a verbal linear equation and solution.

The HEAT Project's primary goal was to provide immediate perceptible boosts to participants' performance in one of the critical foundations of algebra (National Mathematics Advisory 
Panel, 2008). We also tracked subsequent academic performance of participants as measured by ACT composite score, ACT math score, and Louisiana's end of course (EOC) Algebra I exam. As such, this paper seeks to determine the relationship between HEAT competition performance and performance on the abovementioned assessments.

\section{Methodology}

\subsection{Research Context and Participants}

In this study, conducted from 2011-2016, the HEAT project provided six, high poverty middle schools with large populations of African American students with supplemental mathematics instruction focused on Algebra. Each participating middle school's composition included at least $75 \%$ students from minority groups and $75 \%$ students on free/reduced lunch. The HEAT project is one component of the U.S. Department of Education GEAR UP (Gaining Early Awareness for Undergraduate Programs) Grant partnership between an urban school district and a university. Prior to the start of the project, participating teachers engaged in a professional development seminar focused on mastering concrete and pictorial approaches modified from Borenson's Hands-On Equations model. Following the professional development, teachers recruited 127 students from their schools and worked with them for 15-20 hours after school throughout the semester. All students received the same intervention, in which they utilized the Hands-On Equation models and pictorial representations to set up and solve linear equations with one unknown. At the end of the semester, a final HEAT competition was held at the university so that students could demonstrate their knowledge of using the Hands-On equation models and pictorial representations to solve linear equations with one unknown. Students' pictorial and Hands-On equation models were graded. Each student obtained three scores: A score on using the Hands-On Equations models (concrete test score), a score on using pictorial representations (pictorial test score), and a combined score: The sum of the concrete and the pictorial scores.

All data were collected after participants anticipated cohort graduation date in 2016. The data for this study is comprised of the students' pictorial and concrete scores obtained from the HEAT competition along with students' scores from standardized tests, including: ACT composite score and ACT math score (taken at the end of the 11th grade year as per state requirements) and End of Course (EOC) algebra I score (administered after completion of 9th grade Algebra I course) obtained from the school district. The ACT composite score is an average of the four multiple-choice subject tests scores: math, science, English, and reading. It is rounded to the nearest whole number and reported with two dashes if a student left any subject test completely blank. The ACT math subject test measures a student's preparedness for higher math (number quality, algebra, functions, geometry, statistics and probability), their ability to integrate essential skills, and modeling. These subject tests are scored by counting the number correct and converting that number to a score that ranges from one to thirty-six. As a result, the composite score also ranges from one to thirty-six (ACT, 2017). Algebra I EOC assesses student knowledge of functions, numbers, quantity, statistics and probability. Students are rated in one of four categories: Needs improvement, fair, good, and excellent (Louisiana Department of Education, 2018). 


\subsection{Findings and Analysis}

To examine the relationship between performance in the HEAT Project and subsequent measures of mathematics achievement, we drew from a dataset containing eighth grade HEAT competition scores from all 127 participants, of which 29 participants $(22.8 \%)$ had missing values in one or more of the variables tracking high school performance. These missing values were classified as missing not at random (MNAR) because participants either moved, dropped out, were home schooled, obtained a General Education Development (GED) diploma, or were not in the system. Prior to conducting regression analysis, the modified dataset was screened for outliers, additional missing values, and normality. Univariate outliers were detected within the following variables: ACT composite score $(1 \geq 0)$, ACT math score $(1 \geq 0 ; 1 \leq$ 128). While each of these outliers had the ability to overly influence the modified data set, they were retained because they reflect the variability that exists among student test scores. In addition, there were not any cases of multicollinearity because the variance inflation factor (VIF) was 2.29 and within an acceptable range (less than 10.0). However, the distribution of both dichotomous variables, EOC Algebra, whose frequencies of $84.5 \%$ may bias findings. Yet, this distribution also indicated a large majority of HEAT participants scored at the two highest levels (labeled "Good" or "Excellent") on their EOC exams.

One missing value was still present in the modified dataset for Algebra EOC scores, but it was missing completely at random (MCAR) because the pattern of missing values cannot be predicted based on another variable (Wayman, 2003). While these values were a relatively small proportion of the dataset, they still had the potential to impact the ability to make valid inferences (Tabachnick \& Fidell, 2007). As a result, these missing values were treated using multiple imputation in order to predict missing values while producing unbiased parameter estimates and restoring the natural variability within the data (Wayman, 2003). The predicted values were calculated using the average of twenty imputed values produced using the Stata 12 statistical package.

After treating missing values, the dataset was screen for normality. Based on the examination of skewness and kurtosis values, two variables were substantially positively skewed, which are presented in Table 2. A log transformation was performed to treat the lack of normality within the ACT Math and Final GPA variables.

Table 2. Means, Standard Deviations, Skewness, and Kurtosis

\begin{tabular}{|l|l|l|l|l|}
\hline Variable & Mean & Standard Deviation & Skewness & Kurtosis \\
\hline ACT Composite & 20.4952 & 4.6902 & -1.2903 & 8.3515 \\
\hline ACT Math & 21.3689 & 11.6181 & 7.4890 & 70.4964 \\
\hline
\end{tabular}

Note. Descriptive statistics for the ACT Composite and ACT Math variable. 


\subsubsection{ACT Composite}

Regression analysis was performed to examine the relationship between the ACT Composite and HEAT competition scores indicates that the overall model was statistically significant $F(2$, $100)=12.71, \mathrm{p}<.001$, which accounted for $20.2 \%$ of the model's, $\left(\mathrm{R}^{2}\right)$ equaled .2026 (adjusted $\mathrm{R}^{2}=.1867$ ), variance in the regression model. This demonstrates a positive relationship between the HEAT project participants' competition scores and their overall ACT Composite score. The pictorial portion of the HEAT $8^{\text {th }}$ grade competition was the only statistically significant portion of the project in predicting a participant's performance on the entire ACT college entrance exam as measured by the composite score. This portion of the HEAT competition also had the greatest influence on student ACT composite performance, which is indicated by the larger standardized beta and semi-partial correlation coefficients.

Table 3. ACT Composite Unstandardized Regression Coefficients (B) and Intercept, Standardized Regression Coefficients $(\beta)$, Semipartial Correlations $\left(\mathrm{sr}_{\mathrm{i}}\right)$, t-values, $\mathrm{p}$-values

\begin{tabular}{|l|l|l|l|l|l|}
\hline & $\mathrm{B}$ & $\beta$ & $\mathrm{sr}_{\mathrm{i}}$ & t-value & $\mathrm{p}$-value \\
\hline (Constant) & 16.452 & & & 14.89 & 0.000 \\
\hline Session I Pictorial & 0.101 & 0.094 & 0.183 & 2.05 & 0.043 \\
\hline Session II Manipulative & 0.148 & 0.081 & 0.135 & 1.51 & 0.135 \\
\hline
\end{tabular}

Note. Results of regression analysis examining the relationship between HEAT competition pictorial and manipulative session scores and ACT Composite scores.

\subsubsection{ACT Math}

While the regression analysis was performed with the untreated variable, it was not statistically significant, but could be considered to be approaching statistical significance, $p=.07$. The overall model using the transformed data was statistically significant $F(2,100)=8.31, \mathrm{p}<.001$. The variance accounted for in this model was $14.25 \%,\left(\mathrm{R}^{2}\right)$ equaled .1425 (adjusted $\mathrm{R}^{2}$ $=.1254$ ). This indicates that the relationship between HEAT participant's $8^{\text {th }}$ grade competition performance is positively correlated with their ACT Math scores. It should also be noted that while the overall model was significant only the Session I pictorial scores were statistically significant, $\mathrm{p}<.05$. As with the composite score, this segment of the HEAT competition had the greatest influence on a participant's ACT Math performance as determined by the larger standardized beta and semi-partial correlations coefficients. 
Table 4. ACT Math Unstandardized Regression Coefficients (B) and Intercept, Standardized Regression Coefficients $(\beta)$, Semipartial Correlations $\left(\mathrm{sr}_{\mathrm{i}}\right)$, t-values, $\mathrm{p}$-values

\begin{tabular}{|l|l|l|l|l|l|}
\hline & $\mathrm{B}$ & $\beta$ & $\mathrm{sr}_{\mathrm{i}}$ & $\mathrm{t}$-value & $\mathrm{p}$-value \\
\hline (Constant) & 2.7005 & & & 22.46 & 0.000 \\
\hline Session I Pictorial & 0.0137 & 0.2349 & 0.2349 & 2.54 & 0.013 \\
\hline Session II Manipulative & 0.0022 & 0.0192 & 0.0192 & 0.21 & 0.836 \\
\hline
\end{tabular}

Note. Results of regression analysis examining the relationship between HEAT competition pictorial and manipulative session scores and ACT Math scores.

\subsubsection{End of Course Algebra I}

Regression analysis was performed to examine the relationship with EOC Algebra I variable (0 $=$ Fair or below, $1=$ Good or Excellent), which was dummy coded. The overall model was statistically significant $F(2,100)=6.77, \mathrm{p}<.01$. The variance accounted for in this model was $11.92 \%$, $\left(\mathrm{R}^{2}\right)$ equaled .1192 (adjusted $\mathrm{R}^{2}=.1016$ ). This model indicates the relationship between HEAT participant's eighth grade competition performance is positively correlated participants' performance on their Algebra I end of course exam. Whereas the overall model was statistically significant, only the Session I pictorial overall scores were statistically significant, $\mathrm{p}<.05$. Again, this segment of the HEAT eighth grade competition had the greatest influence, as determined by the larger standardized beta and semi-partial correlations coefficients, on whether a participant's Algebra I exam score is in either of the top two categories of good or excellent. Conversely, analysis also indicated a negative relationship between EOC Algebra I scores and the Session II manipulative portion of the competition.

Table 5. EOC Algebra I Unstandardized Regression Coefficients (B) and Intercept, Standardized Regression Coefficients $(\beta)$, Semipartial Correlations $\left(\mathrm{sr}_{\mathrm{i}}\right)$, t-values, $\mathrm{p}$-values

\begin{tabular}{|l|l|l|l|l|l|}
\hline & $\mathrm{B}$ & $\beta$ & $\mathrm{sr}_{\mathrm{i}}$ & t-value & $\mathrm{p}$-value \\
\hline (Constant) & 0.7313 & & & 8.11 & 0 \\
\hline Session I Pictorial & 0.0120 & 0.4220 & 0.279 & 2.97 & 0.004 \\
\hline Session II Manipulative & -0.0064 & -0.1132 & -0.0749 & -0.8 & 0.427 \\
\hline
\end{tabular}

Note. Results of regression analysis examining the relationship between HEAT competition pictorial and manipulative session scores and End of Grade Algebra I.

The examination of eighth grade participants' high school performance, as measured by their standardized test scores and final GPA, indicates an overall positive relationship with HEAT competition scores. The Session I pictorial portion of the project's eighth grade competition 
was a relatively consistent predictor of participants' high school standardized scores since it was found to be significant on both ACT Composite and Math scores along with the Algebra I EOC. Additionally, the pictorial portion indicated that as participant's competition scores increased so did their ACT composite and ACT math. This session also indicated that the probability of participant earning an EOC Algebra I score of "good" or "excellent" increased along with their competition scores. Thus, the pictorial sessions rather than the manipulative sessions are a primary indicator of eighth grade participants' understanding of algebraic concepts and future performance on standardized math exams.

\section{Discussion and Conclusion}

The aim of this study was to examine the relationship between students' HEAT competition performance and their subsequent mathematics achievement. Based on these findings, the pictorial portion of the HEAT project was a contributor to participants' algebraic performance on Algebra EOC and ACT Math, which both included significant content related to linear equations - a centerpiece of the HEAT project's content. While we recognize the statistical analysis verifies this conjecture, we also want to stress that other contextual and instructional factors beyond the scope of this study could have conceivably influenced subsequent academic performance of HEAT participants.

The concrete use of manipulatives in the HEAT Project was necessary, but not sufficient as a predictor of future mathematics achievement. Bruner's (1966) work supports this notion, in that he views the enactive stage (students using concrete materials to model mathematical ideas) as a prerequisite for conceptual development in the iconic stage (pictures and drawings). Moreover, our findings appear to synchronize with the work of Sherman, Walkington, and Howell (2016), who conjectured that a "verbal precedent view (VPV), in which verbal reasoning abilities and language skills precede the ability to use symbols meaningfully, may better describe the development of students' understanding of algebra" (p. 135). It is worth noting that the concrete portion of the HEAT competition was predominantly straightforward algebraic equations without context, whereas the pictorial segment of the competition included context and often times included a cultural connection. A concrete problem using manipulatives read as follows: $4(-x)+5 x=2(-x)+x-16$. Conversely, one of the pictorial problems read as follows:

Drew Brees has thrown 23 touchdowns this season. If the number of touchdowns Lance Moore has caught from Drew Brees were tripled and increased by five it would be the same number of touchdowns Drew Brees has thrown. How many touchdowns has Lance Moore caught from Drew Brees?

Therefore, the authors suspect that the compounding effects of more visual representation, problem complexity, and social/cultural connections may have contributed to the difference in connections to subsequent mathematics achievement. Nevertheless, the results are viewed as a promising sustainable framework for developing algebraic thinking and reasoning. At a minimum, the HEAT Project results will contribute to conversations centered on ways to expose urban students to creative, social, hands-on pedagogy in low-stakes, social contexts in order to position students for both immediate and long-term mathematics success, without 
sacrificing intellectual rigor. The bulk of efforts to assist students in urban schools, nationwide, focus on help after students fail (a remedial approach); whereas HEAT focused on providing students with a head start on the algebra they were expected to know in the future. Therefore, a further suggestion is scaled-up research and intervention (as opposed to remediation) efforts targeted to specific fundamentals of algebra and its prerequisites. Further analysis should also include student contextual and teacher instructional factors, among others, so as to gain a more holistic view of the impact of this project and those similar to it.

\section{References}

ACT (American College Testing). (2016). The Condition of STEM 2016. Retrieved on October 1, 2016, from http://www.act.org/content/dam/act/unsecured/documents/STEM2016_52_ National.pdf

ACT (American College Testing). (2017). Using Your ACT Results. Retrieved on November 1, 2017, from https://www.act.org/content/dam/act/unsecured/documents/UsingYourACTResult s2017-18.pdf

Araya, R., Calfucura, P., Jiménez, A., Aguirre, C., Palavicino, M. A., Lacourly, N., ... Dartnell, P. (2010). The effect of analogies on learning to solve algebraic equations. Pedagogies: An International Journal, 5(3), 216-232. https://doi.org/10.1080/1554480X.2010.486160

Borenson, H., \& Barber, L. W. (2008). The effect of Hands-On Equations on the learning of algebra by 6th, 7th and 8th grade inner city students. Retrieved January 5, 2017, from http://www.source-secure.com/Portals/25/Interim10ReportDec010-2008-6th7th8th-innercity. pdf

Bruner, J. S. (1961). The act of discovery. Harvard Educational Review, 31(1), 21-32.

Bruner, J. S. (1966). Toward a theory of instruction (Vol. 59). Harvard University Press.

Bruning, R. H., Schraw, G. J., \& Ronning, R. R. (1999). Cognitive psychology and instruction (3rd ed.). Columbus: Prentice Hall.

Ernest, P. (1994). Social constructivism and the psychology of mathematics education. Constructing Mathematical Knowledge: Epistemology and Mathematical Education, 62-71.

Greeno, J. G., Collins, A. M., \& Resnick, L. B. (1996). Cognition and learning. Handbook of Educational Psychology, 77, 15-46.

Jackson, K., \& Wilson, J. (2012). Supporting African American students' learning of mathematics: A problem of practice. Urban Education, 47(2), 354-398. https://doi.org/ $10.1177 / 0042085911429083$

Louisiana Department of Education. (2018). LEAP 2025 Algebra I and Geometry Assessment. Retrieved from https://www.louisianabelieves.com/docs/default-source/assessment-guidance/ leap-2025-algebra-i-and-geometry-assessments.pdf?sfvrsn=3

Matthews, L. E. (2008). Illuminating urban excellence: A movement of change within mathematics education. Journal of Urban Mathematics Education, 1(1), 1-4. 


\section{Macrothink}

McMahon, M. (1997). Social constructivism and the World Wide Web-A paradigm for learning (Vol. 327). ASCILITE Conference, Perth, Australia.

National Academy of Sciences, National Academy of Engineering, and Institute of Medicine. (2011). Expanding underrepresented minority participation: America's science and technology talent at the crossroads. Washington, D.C.: The National Academies Press.

National Assessment of Educational Progress. (2016). National results overview. Retrieved from https://www.nationsreportcard.gov/reading_math_2015/\#mathematics?grade $=4$

National Mathematics Advisory Panel. (2008). Foundations for success: The final report of the National Mathematics Advisory Panel. Washington, D.C.: National Academies Press.

National Research Council. (2015). Identifying and supporting productive STEM programs in out-of-school settings. Washington, D.C.: The National Academies Press.

Prawat, R. S., \& Floden, R. E. (1994). Philosophical perspectives on constructivist views of learning. Educational Psychologist, 29(1), 37-48. https://doi.org/10.1207/s15326985ep2901_4

Sherman, M., Walkington, C., \& Howell, E. (2016). A Comparison of Symbol-Precedence View in Investigative and Conventional Textbooks Used in Algebra Courses. Journal for Research in Mathematics Education, 47(2), 134-146. https://doi.org/10.5951/jresematheduc. 47.2.0134

Tabachnick, B. G., \& Fidell, L. S. (2007). Using multivariate statistics (5th ed.). Boston: Pearson Education, Inc.

Vlassis, J. (2002). The balance model: Hindrance or support for the solving of linear equations with one unknown. Educational Studies in Mathematics, 49(3), 341-359. https://doi.org/ 10.1023/A:1020229023965

Vygotsky, L. S. (1978). Mind in society: The development of higher psychological processes. Cambridge, MA: Harvard University Press.

Wayman, J. C. (2003). Multiple imputation for missing data: What is it and how can I use it? Paper presented at the 2003 Annual Meeting of the American Education Research Association, Chicago, IL.

Wertsch, J. V. (1988). Vygotsky and the social formation of mind. Cambridge, MA: Harvard University Press.

Wolfgang, C. H., Stannard, L. L., \& Jones, I. (2001). Block play performance among preschoolers as a predictor of later school achievement in mathematics. Journal of Research in Childhood Education, 15(2), 173-180. https://doi.org/10.1080/02568540109594958 


\section{Copyright Disclaimer}

Copyright for this article is retained by the author(s), with first publication rights granted to the journal.

This is an open-access article distributed under the terms and conditions of the Creative Commons Attribution license (http://creativecommons.org/licenses/by/3.0/). 